Editorial

Special Edition | Reflection and Reflective Thinking

(C) Journal of International Students

Volume 10, Issue S2 (202X), pp. i-v

ISSN: 2162-3104 (Print), 2166-3750 (Online)

ojed.org/jis

\title{
International Students, Reflection, and Employability
}

\author{
Mary Ryan \\ Macquarie University, Australia \\ Georgina Barton \\ University of Southern Queensland, Australia
}

\begin{abstract}
International students make an incredibly important contribution to universities worldwide. It is therefore critical that higher education contexts support international students' success in their studies. The International Student Barometer indicates international students' interest in work experience, career advice and employment post-study. A necessary skill for all graduates is the ability to be able to reflect on and in professional practice, yet there is limited research that explores reflection, the teaching of reflective thinking, and reflexivity for international students. Our research has shown that international students may approach the process of reflection differently due to their cultural differences so it is important that universities acknowledge and consider further ways in which to teach and assess reflection for international students. This special issue shares 7 papers related to international students and reflection by drawing on Rodgers' four functions of reflection. We hope that the special issue is of value to the journal's readership, particularly in regard to assisting both academic and support staff in universities with their work on reflection with international students.
\end{abstract}

Keywords: international students, reflection, reflexivity, employability

In this special issue we explore the importance of reflection and reflective thinking for international students in a range of contexts. For many educational programs in 
universities, reflection and reflective thinking are critical skills required to meet graduate attributes and professional standards, ensuring employability (Treleaven \& Voola, 2008). Even though there is a significant amount of research that has explored the importance of reflection in the higher education context (Moon, 2001; Smith, 2011), including in specific discipline areas (Barton \& Ryan, 2013; Mann et al., 2009), there is limited scholarly work that addresses how international students reflect or what approaches to teaching and assessing reflection might best support international students for post-study employment.

The editors of this special issue have conducted prior research on reflection and international students noting that reflection is a "common expectation for learners in higher education, both informally in the hope that learners will reflect and act upon feedback provided and also in formal assessment tasks and work integrated learning experiences" (Barton \& Ryan, 2017, p. 93). However, higher education contexts and workplaces may assume and implement set approaches to reflection for all students which might not align with international students' understanding and knowledge about reflective practice. In some of our work on reflection in higher education we explored multimodal methods, arguing that different disciplines may also view reflection in different ways (Barton \& Ryan, 2013). It is critical that higher educators consider culturally-appropriate ways to reflect for international students as this acknowledges and embraces diverse ways of thinking.

It is still important to define reflection when comprehending different ways to think and act reflectively. Hatton and Smith's (1995) early work in teacher education presented a number of definitions of reflection, arguing some difficulty in pinning down an absolute definition. They drew on foundational work by Dewey (1993) and offered different perspectives and purposes of reflection from the literature. These included reflection as critical thought versus practice (Gore \& Zeichner, 1991; Schön, 1983, 1987), problem solving (Adler, 1991; Calderhead, 1989) and strategies to teach reflection. They conclude by sharing different purposes of reflection including reflecting in and on action (Schön, 1983) and reflection as a technical rationality (Van Manen, 1977) in which certain decision making processes are engaged. They argue that reflective practice can be shared by students descriptively, dialogically and/or critically.

For the purpose of this special issue Rodgers (2002) four functions of reflection will be explored in each paper. These functions include reflection as: a meaning-making process, a rigorous way of thinking, being important in and for community and, a set of attitudes. Authors have also considered other models where appropriate. The Special Issue explores how the four functions might look different in these diverse contexts. Basing each chapter on a specific framework such as Rodgers (2002), allows an in-depth examination of diverse reflective practices. We are also interested in knowing not only the different ways teachers of international students teach reflection and how international students reflect, but also how these attributes contribute to international students' preparedness for work experience as well as the implications for employability post-graduation.

Contributors come from a range of countries and contexts and have been involved in comprehensive work with international students for some time. They are committed to embedding the practice of reflection when working with international 
students throughout their studies. As stated previously, a significant amount of scholarly work focuses on how to improve learning teaching and learning in higher education related to reflection, however, there is limited research exploring reflection and reflective thinking when working with international students. We believe that it is critical to consider reflective practices and its affordances for international students, given their importance in many universities globally.

The Special Issue takes a strengths-based rather than a deficit view of this topic as international students bring unique perspectives and capacities for learning and employment in and beyond higher education contexts. Barton and Ryan lead off the issue with a conceptualization of what reflective thinking and reflexive practice look and feel like for international students. They illustrate the importance of contextually relevant strategies to enable success and employability for international students with diverse and complex needs and goals. In the second paper, Snepvangers and O'Rourke explore the collaborative dynamics of international students, staff and industry partners using a community building framework for work integrated learning (WIL) to simulate the 'gig economy'. They focus on the development of transferable skills of creative and critical thinking through intercultural learning and show how to plan an academic creative practice WIL program for mentors. Uusimaki and Garvis use reflections to understand how international students studying in Sweden experience course structures, learning and teaching practices and relationship development with their lecturers. Despite a growth in international students in Sweden, there is a dearth of research in this area. They found that expectations differ across countries and it is important to provide induction sessions that include approaches to learning and teaching, and building relationships with academic staff.

Multi-socialization is a reality that many international students face (Barton et al., 2017). Socializing into a new country, a new culture, a new university setting, and sometimes, a new WIL setting, means that reflection is essential to manage the demands of multiple expectations. The fourth paper, by Hartwig, Stokhof and Fransen, investigates multi-socialization for teacher education students in The Netherlands. They found that reflection enabled students in their development as global citizens and global teachers. Finn, Phillipson and Goff similarly report on international teacher education students. In contrast, however, their participants engaged in a simulated practicum classroom experience in Australia. They investigated how international students drew on their cultural identities to reflect on their teaching practice. International students in this study negotiated the intersections of culture and pedagogy in diverse school classrooms, within the 'safe space' of a virtual reality simulation. Such an experience does, however, require an additional level of socialization into a virtual space.

The final two papers in this special issue focus on employability for international students. In the sixth paper, Fakunle and Pirrie explore international students' perceptions of developing their employability while studying in the UK. The draw discursive connections between internationalization and employability, two concepts that tend to be disconnected in policy and discourse. They recommend a more systemic approach to embedding employment development opportunities in courses. The final paper, by Watson and Barton, seems most timely in the current COVID-19 pandemic. It focuses on international students' wellbeing and 
employability using arts-based methods to help them think positively about their studies and future working lives. They found that arts-based methods of reflection enabled a 'community of respect' and prompted culturally appropriate sharing of challenges and what mattered most to these international students in the context of a global crisis.

Rodgers' four functions of reflection have proven to be a generative and illuminating framework to investigate the experiences of international students and academics around the world. This special issue demonstrates creative and critical approaches to reflection in different multi-socialization experiences. A common theme across these papers is the importance of explicitly embedding culturallyappropriate reflection into the learning of international students so they have the tools to negotiate the complex demands of international study in sustainable and fulfilling ways.

\section{REFERENCES}

Adler, S. (1991). The reflective practitioner and the curriculum of teacher education. Journal of Education for Teaching, 17(2), 139-150.

Barton, G. \& Hartwig, K. (2017). Professional learning in the work place for international students: Exploring theory and practice. Cham, Switzerland: Springer.

Barton, G. M., \& Ryan, M. (2013). Multimodal approaches to reflective teaching and assessment in higher education: a cross disciplinary approach in Creative Industries. Higher Education Research and Development, 33(3), 409-424.

Barton, G. M., Hartwig, K., Bennett, D., Cain, M., Campbell, M., Ferns, S., Jones, L., Joseph, D., Kavanagh, M., Kelly, A., Larkin, I., O'Connor, E., Podorova, A., Tangen, D., \& Westerveld, M. (2017). Work placement for international students: A model of effective practice. In G. M. Barton \& K. Hartwig (Eds.), Professional Learning in the Work Place for International Students: Exploring Theory and Practice, (pp. 13-34). Springer Publishers.

Barton, G. M., \& Ryan, M.E. (2017). Reflection and reflective practice for international students and their supervisors in context. In G. M. Barton \& K. Hartwig (Eds.), Professional Learning in the Work Place for International Students: Exploring Theory and Practice, (pp. 93-110). Springer Publishers.

Calderhead, J. (1989). Reflective teaching and teacher education. Teaching and Teacher Education, 5(1), 43-51.

Dewey, J. (1933). How we think: A restatement of the relation of reflective thinking to the educative process, vol. 8. Boston: D. C Heath

Gore, J. M., \& Zeichner, K. M. (1991). Action research and reflective teaching in preservice teacher education: A case study from the United States. Teaching and Teacher Education, 7(2), 119-136.

Hatton, N., \& Smith, D. (1995). Reflection in teacher education: Towards definition and implementation. Teaching and Teacher Education, 11(1), 33-49. 
Mann, K., Gordon, J., \& MacLeod, A. (2009). Reflection and reflective practice in health professions education: a systematic review. Advances in Health Sciences Education, 14(4), 595-621.

Moon, J. (2001). PDP working paper 4: Reflection in higher education learning. Higher Education Academy, 1-25.

Rodgers, C. (2002). Defining reflection: Another look at John Dewey and reflective thinking. Teachers College Record, 104(4), 842-866.

Schön, D. A. (1983). The reflective practitioner: How professionals think in action. New York: Basic Books, Inc.

Schön, D. A. (1987). Educating the reflective practitioner. San Francisco: JosseyBass.

Smith, E. (2011). Teaching critical reflection. Teaching in Higher Education, 16(2), 211-223.

Treleaven, L., \& Voola, R. (2008). Integrating the development of graduate attributes through constructive alignment. Journal of Marketing Education, 30(2), 160-173.

Van Manen, M. (1977). Linking ways of knowing with ways of being practical. Curriculum Inquiry, 6(3), 205-228.

MARY RYAN, PhD, is Professor and Dean of Education at Macquarie University, Sydney, Australia. Her research is in the areas of teachers' work in, and preparation for, diverse classrooms, reflexive learning and practice, writing pedagogy and assessment and reflective writing. She led a highly successful Australian Learning and Teaching Council grant $(2010 / 11)$ on reflective learning across disciplines in higher education. Her current Australian Research Council Discovery projects are in the areas of classroom writing and preparing reflexive teachers for diverse classrooms. She is a Principal Fellow of the Higher Education Academy in the UK. Email: mary.ryan@mq.edu.au

GEORGINA BARTON, PhD, is a Professor and Associate Head - Research in the School of Education at the University of Southern Queensland, Brisbane, Australia. Before being an academic, Georgina taught in schools for over 20 years including teaching English in South India with Australian Volunteers International. Georgina also has extensive experience in teaching the arts in schools and universities and often utilizes the arts to support students' literacy learning outcomes. She has over 130 publications including as the lead editor of a book titled Professional Learning for International Students: Exploring Theory and Practice. She is a Principal Fellow of the Higher Education Academy in the UK. Email: georgina.barton@usq.edu.au 